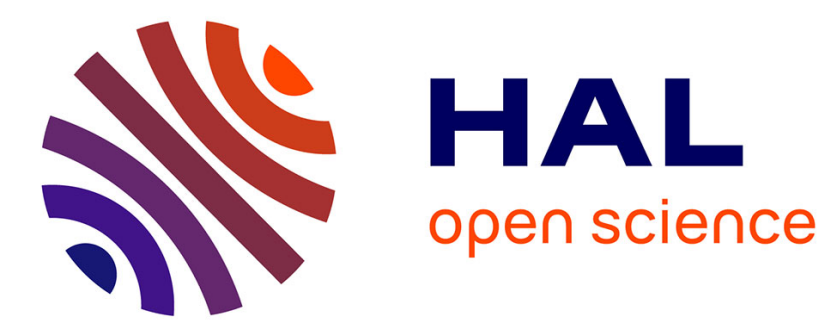

\title{
Categorizing Engineer-to-Order Companies Through Their Project Execution Strategy
}

Kristina Kjersem, Gabriele H. Jünge

\section{To cite this version:}

Kristina Kjersem, Gabriele H. Jünge. Categorizing Engineer-to-Order Companies Through Their Project Execution Strategy. IFIP International Conference on Advances in Production Management Systems (APMS), Sep 2016, Iguassu Falls, Brazil. pp.919-926, 10.1007/978-3-319-51133-7_108 . hal01615764

\section{HAL Id: hal-01615764 \\ https://hal.inria.fr/hal-01615764}

Submitted on 12 Oct 2017

HAL is a multi-disciplinary open access archive for the deposit and dissemination of scientific research documents, whether they are published or not. The documents may come from teaching and research institutions in France or abroad, or from public or private research centers.
L'archive ouverte pluridisciplinaire HAL, est destinée au dépôt et à la diffusion de documents scientifiques de niveau recherche, publiés ou non, émanant des établissements d'enseignement et de recherche français ou étrangers, des laboratoires publics ou privés. 


\title{
Categorizing Engineer-To-Order Companies through their Project Execution Strategy
}

\author{
Kristina Kjersem ${ }^{1}$, Gabriele H. Jünge ${ }^{2}$ \\ 1 Møreforsking Molde AS, Norway \\ kristina.kjersem@himolde.no \\ 2 Norwegian University of Science and Technology, Trondheim, Norway \\ gabriele.junge@ntnu.no
}

\begin{abstract}
One of the main characteristics of engineer-to-order (ETO) manufacturing companies is that they are project organized and, by definition, each project is a unique endeavor [1]. The implication of this characteristic reflects in that most of the ETO companies apply own execution strategies to their projects. However, these strategies do not always fit the complexity of ETO projects that usually are phase-based managed and involve several participants in each of the phases. This research paper proposes a new categorization of ETO companies based on the project execution strategy applied by our case companies. The scope of such categorization is to support practitioners in defining their strategies for managing ETO projects.
\end{abstract}

Keywords: ETO categorization. Project execution strategy $\cdot$ Manufacturing companies

\section{Introduction and Background}

Engineer-To-Order (ETO) is a manufacturing approach where each artifact is customized (from the early design phase throughout the production and delivery phases) according to buyer's preferences. Main characteristics of ETO manufacturing approach are: low-volumes, high degree of customization and project-based environment [2]. In a comprehensive literature review presented by [3], the authors outline the commonalities and differences between different types of ETO supply chain. The first commonality is that ETO operates in a project-based environment while the second one is that it results in unique artifacts. Among the differences between ETO approaches can be the reusage of the same design versus creating a new one for each product. Another difference is sector specific like for example in construction, where the team complete the project on a new site each time, whereas in shipbuilding the product is manufactured at the same site [3]. One implication of the first commonality is that each ETO company must apply an own project execution strategy to manufacturing their products. However, in $[4,5]$ the authors state that traditional project management approaches do not take into consideration the challenges of ETO environment. Among these challenges, [4] name the network organized 
projects, iteration of design/engineering activities and concurrent engineering. A network-organized project involves a large number of project participants who do not necessary belong to the company responsible for managing the whole project. Most of the ETO projects involve a large number of participants since more than seventy-five percent of the product's value is built with help from suppliers and subcontractors. Consequently, the company that manages the entire project executes only a small part of the project with own employees and at own facilities [6], which makes difficult to control all activities during the project. However, according to our empirical data, several case companies seem interested in developing project execution strategies that can give them better control over most of the project phases. We define project execution strategy (PES) as the management approaches applied by ETO organizations in order to plan, control and complete a project according to customer's requests. PES is influenced by the company's decision about who performs each activity and where each phase of the project is scheduled for completion.

Based on earlier research projects conducted by Møreforsking Molde AS (a Norwegian research institute), as well as on its long-term analysis of the Norwegian maritime cluster, this paper brings to discussion a new categorization of the ETO type of manufacturing. The background for this study comes from projects where our customers were interested in improving their PES for managing ETO projects. These companies were using traditional project management approaches that needed to be adapted to the challenges of the ETO environment and we learned that any PES must contain both standardized elements as well as customized features. Thus, we attempted to find a categorization of ETO companies by the strategies used during their project execution. The closest categorization we found is the one presented by Hicks et al., [7] where the authors use a similar line of thought. Nevertheless, their categorization is from a high-level management perspective and do not address the project management approached by their case companies. To our knowledge, there is no other studies categorizing ETO companies by their project execution strategies.

From our portfolio of companies, we selected ten cases manufacturing different ETO products and studied the similarities and differences between their PESs. Consequently, we identified different levels of integration between project phases as well as different strategies for managing these and that point toward a new categorization of ETO companies from the perspective of PES. In this paper, we first describe the models of PESs identified from our empirical data and based on these we group ETO companies in three categories that are relevant from the proposed perspective. The scope of this categorization is to highlight the need for integrated PES that fit different ETO challenges. A second scope of the categorization is to serve as a decision support for project managers when planning the strategy for delivering new ETO products. This is an important aspect when it comes to optimizing the project execution as a whole and not only some of its phases. In the following, we present a short review of the literature we found on ETO categorization. 


\section{Literature Review}

Willner et al., [8] present a relevant literature review on categorization of ETO companies and according to their findings each classification contains a different ETO perspective like: type of modularization, point of customer involvement, engineer dimension referring to the number of standardized versus customized parts, etc. The same authors propose a categorization based on the complexity of the ETO product where they considered the following two factors: 1) the number of units sold annually and 2) the number of engineering hours used for producing the artifact. Their categorization resulted in a matrix of four groups: 1) Complex ETO, 2) Basic ETO, 3) Repeatable ETO and 4) Non-Competitive ETO [8]. This categorization is suitable at a high-level management when deciding strategies at the company level. Nevertheless, this matrix contributes to better understanding of the diversity of ETO products and the authors propose appropriate strategies for improving the outcome of such projects.

Cigolini et al., [9], categorizes ETO companies based on how the product design affects the timing for sourcing decisions. They identified three types of innovativeness: 1) pure incremental innovation, 2) only technology innovation, 3) technology and marketing innovation, which affect the timing of decision for sourcing activities. Suppliers in the third category are earlier involved in the project.

Another relevant categorization is presented by Hicks et al., [7], who use physical processes and the depth of the product structure for identifying four types of ETO companies specific to UK business environment. These are: 1) vertically integrated, 2) design and assembly, 3) design and contract, and 4) project management. However, these ideal types are quite general, especially when describing their project management approach. We have not identified these types of company among our case companies or other previous projects. To our knowledge, there is no ETO categorization that takes into consideration both the typical phase-based project environment as well as who performs each of the project phases. The categorization presented here is based on the processes defined by our case companies for managing each phase of their projects.

\section{$3 \quad$ Methodology}

The case companies have all had different research projects together with our institute. Through these projects, we performed both value and supply chain analysis, which means that our database is quite extensive. The selected companies manufacture different ETO products like offshore and fishing vessels, cranes, winches and alike. The criteria for selecting these cases was mainly their interest in research projects aiming to improve their project management strategies. We have sent the figures to several of the companies and receive feedback on the phases used for defining the project execution strategy. Moreover, the authors work closely through their PhD studies with several of the case companies. The scope of this study is to explore the factors that contribute to the complexity 
of project execution strategy in ETO environment. Exploratory case studies as defined by $[10,11]$ are reckoned as particularly suitable for this type of research. Case studies are suited for capturing knowledge from practitioners and use these to develop new theories $[11,12]$.

\section{ETO Project Phases}

In order to grasp the intricacy of the ETO projects, we decided to map the most significant phases that influence the strategy applied to manage these projects. Several internal and external suppliers must deliver information, technical documentation - on specific systems and equipment - during each of the project phases described here. We illustrates each project phase in Figure 1, and describe them next.

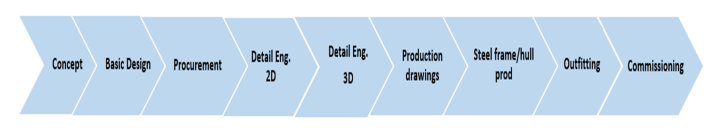

Fig. 1. Project phases

During the concept phase, a company develop a new product either by own internal projects or by collaborating with customers interested in improving their own business quality. Basic Design is an activity performed by the project responsible company in collaboration with the customer who is interested to decide and approve the main features of the product. This phase contains both 2D drawings and 3D models and some of the case companies chose to outsource partly or entire 3D modelling activities. The company who is responsible for managing the project performs usually the procurement activities. However, in some of the cases, the procurement responsibility is divided between two or three project participants (e.g., one company procures the steel and some of the systems, while the leading company buys all major equipment). The company in charge for the whole project performs and delivers $2 \mathrm{D}$ drawings. These types of drawings are considered an important core capability of the company and are very rarely outsourced. Among our cases, there is only one company who does not produce 2D drawings in-house, but collaborate closely with the one producing these drawings.

After completing 2D drawings, these are introduced in a 3D model. The majority of our case-companies perform this phase in-house with own people or people from own subsidiaries. Three of the case companies outsource big parts of 3D modeling activities to other project partners. The reason is that performing such activities necessitates considerable amount of time and resources.

Production drawings represent the drawings used during the production phase. These drawings contain many small details necessary to produce each piece of the product. In some cases, these drawings are produced by the steel frame/hull producing companies, while in other cases, these drawings are produced by the company delivering the basic design and detail engineering. Steel 
frame/hull production phase is in most of the cases outsourced both internal (the main company owns facilities outside Norway) or external (find new collaborating partners in Norway or other countries).

Outfitting and commissioning phases are most of the time performed by the companies managing the whole project. These phases are considered important core capabilities within the company. However, in one of the cases, the company performing these phases is not the one producing the basic design and detail engineering.

\section{$5 \quad$ Mapping Project Execution Strategy}

The table under is a visual presentation of how our case companies have chosen to execute their ETO projects. The colored boxes represent phases performed by partially owned or completely external companies with the symbol "out" as a shortcut for outsourcing. The " $\mathrm{x}$ " symbol confirms in-house execution of the respective phase. The last three columns denote producing equipment (Prod. equip.), procurement (Proc.) and final user. These columns represent an interesting trend among our case companies where at least two of them (A and D) started to produce specialized equipment that was previously supplied by external suppliers (Figure 2).

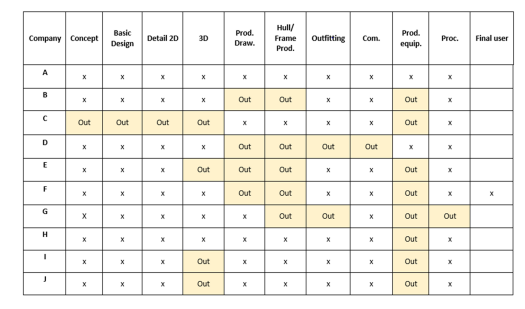

Fig. 2. Map of the project execution strategy phases

The results show a certain similarity in that most of the companies choose to keep in-house the concept, basic design and some parts of the detail engineering phases. However, company $\mathrm{C}$ decided to approach a different strategy and outsourced most of the design, engineering and procurement phases keeping a minimum of engineering hours in-house while producing the steel frame, outfitting and commissioning (the column Com in the table) the final product before delivery. An interesting observation here is that this company seems to achieve quite good results during the present economic crisis. Engineers at company $\mathrm{C}$ work together with the company that deliver the design and engineering phases and give them the production perspective for the solutions applied to the product features. Companies C and D seem to complete each other's project phases in a feasible way. Company $\mathrm{A}$ is the one with a vertically integrated supply chain executing all the project phases in-house. The term in-house refers here to ownership of the process performed in each phase even when the companies 
performing these activities are not located in Norway, but are completely owned by a case company.

Company G, decided to outsource a big part of their procurement activities while company $\mathrm{F}$ decided to outsource the production of steel frame, keeps the outfitting and the commissioning in-house, but they invested in the final phase of the supply chain, namely using the final product in an own subsidiary. Another observation we made during our mapping process is that two of the companies have started to create departments or new subsidiaries that research and develop complex equipment. That means more vertical integration of their supply chains and more risk to be taken when the market is on a down turn. This evolution seem to contrast the trend towards vertical disintegration identified by Hicks et al. [13] several years ago. Analyzing the similarities and differences between our case companies, we identified a common need for dynamic and more integrative PES that would fit the challenges of ETO complex projects.

\section{Categorization}

From the mapping process presented above, we can identify three relevant categories of ETO companies: 1) a vertically integrated type 2) design and engineering type 3) production and testing type.

The vertically integrated companies own most of the processes in each project phase. They acquired smaller local or global companies that deliver services or products able to increase companies' competitive advantage. As a result, the project execution strategy seem more integrated and gives better possibilities for control and improvement. Other advantages are more flexibility for the management of customer change orders and transparency of the practices between project participants. An integrated project execution strategy is also an advantage when ETO companies plan to implement design for manufacturability (DFM) approaches, which is the case for one of the case companies in this study. In order to achieve a better level of DFM, vertically integrated companies consider to start producing own equipment. Among the disadvantages of such approach is that it requires a big organization that is more sensitive to economic downturns. Another disadvantage is that in order to utilize the capacity in a sustainable way, such organizations need a certain number of orders per year [7].

The second category identified in our study is design and engineering type. Companies embracing this strategy own only concept, design and detail engineering in both 2D drawings and 3D modeling. In many of the cases, they outsource also the production drawings to the company producing the steel frame. One advantages of this approach is that the organization is smaller and easy to readjust in times of crisis, which is the case for one of the case companies. Such organizations can also achieve a great deal of flexibility during the design and engineering phases, and less during the production period. Among the disadvantages is the separation from the production facility, which results in less accessibility to lessons learned from this process. Hicks et al., [7] mention also the disadvantage of being dependent upon concurrent procurement, which 
means viable partnership with the suppliers. One case company in this category decided to reduce such dependency and started to produce some of the strategic equipment.

The third category is production and testing (commissioning) where companies decided to focus on core competencies that were outsourced by other companies. The ETO aspect of these companies lays in their ability to find engineering solutions coming from practical experience. These companies reveal a good understanding and translation of customer requirements into practice. The advantages of such approach seem to be a more effective production process and the ability to implement automation on the appropriate processes. One disadvantage is the difficulty to achieve an effective design for manufacturability approach due to a separate ownership between design engineering and production phases. Another disadvantage could be a high dependency on the design company for modifications that require their permissions and participation. However, according to our study, this type of ETO companies seem to be able readjust quite fast during the economic crises.

\section{Discussion and Limitations}

ETO projects need a better management of the involved processes [14] and in order to achieve that we argue that project managers need to apply project execution strategies that take into consideration the complexity of their ETO supply chain. The three categories identified through our study can be useful when managers need to establish the strategy for the execution phase of their projects. The competition within the ETO environment challenges the practitioners to continually improve their manufacturing process so that projects can be deliver in a shorter time, at a lower price while maintaining high quality of the final product $[15,16]$. An efficient and well-adjusted project execution strategy can help ETO companies to achieve such targets. The empirical data suggest that using traditional project management approach is not enough and among the reasons is the number and differences between project participants as well as the iterative nature of design and engineering activities. Our categorization draws attention to the importance of understanding the configuration of the project phases and the necessity to adapt the management strategy to it. A future paper will discuss types of strategies recommended to each of the categories identified in this paper.

The limitations of this research lays in the small number of selected case studies and the fact that most of them are typical Norwegian ETO companies. Similar mapping in other countries might show different results and that would be an interesting research topic. The number of ETO companies grows at a rate of 20 percent per year due to an increasing demand for customized products [17] and so the need for categorization that help us understand which strategies to apply in order to achieve continuous improvement. 


\section{References}

1. PMBOK: A Guide to the Project Management Body of Knowledge (2013)

2. Haartveit, D.E.G., Semini, M., Alfnes, E.: Integration Alternatives for Ship Designers and Shipyards. In: Frick, J., Laugen, B.T. (eds.) Advances in Production Management Systems. Value Networks: Innovation, Technologies, and Management, pp. 309-316. No. 384 in IFIP Advances in Information and Communication Technology, Springer Berlin Heidelberg (2011)

3. Gosling, J., Naim, M.M.: Engineer-to-order Supply Chain Management: A Literature Review and Research Agenda. Int. J. of Produc. Econ. 122(2), 741-754 (2009)

4. Kjersem, K., Emblemsvåg, J.: Literature Review on Planning Design and Engineering Activities in Shipbuilding. In: 22nd Annual Conference of the International Group for Lean Construction. pp. 677-688 (2014)

5. Koskela, L., Howell, G.: Reforming Project Management: The Role of Planning, Execution and Controlling. In: Proceedings of 9th International Group for Lean Construction Conference. pp. 185-198 (2001)

6. Dubois, A., Gadde, L.E.: Supply Strategy and Network Effects-purchasing Behaviour in the Construction Industry. Europ. J. Purchas. \& Supply Manag. 6(3), 207-215 (2000)

7. Hicks, C., McGovern, T., Earl, C.F.: A Typology of UK Engineer-To-Order Companies. International Journal of Logistics 4(1), 43-56 (2001)

8. Willner, O., Powell, D., Gerschberger, M., Schönsleben, P.: Exploring the Archetypes of Engineer-to-order: An Empirical Analysis. International Journal of Operations \& Production Management 36(3), 242-264 (2016)

9. Cigolini, R., Pero, M., Sianesi, A.: When ETO Companies Design the Supply Chain During New Product Development Process. International Journal of Engineering, Science and Technology 6(3), 30-41 (2014)

10. Voss, C., Tsikriktsis, N., Frohlich, M.: Case Research in Operations Management. Int. J. of Oper. \& Produc. Manag. 22(2), 195-219 (2002)

11. Case Study Research: Design and Methods

12. Van Aken, J.E., Romme, G.: Reinventing the Future. Organization Management Journal 6(1), 5-12 (2009)

13. Hicks, C., McGovern, T., Earl, C.F.: Supply Chain Management: A Strategic Issue in Engineer to Order Manufacturing. International Journal of Production Economics 65(2), 179-190 (2000)

14. Mello, M.H., Strandhagen, J.O.: Supply Chain Management in the Shipbuilding Industry: Challenges and Perspectives. Proceedings of the Institution of Mechanical Engineers 225(3), 261-270 (2011)

15. Kjersem, K., Halse, L.L., Kiekebos, P., Emblemsvåg, J.: Implementing Lean in Engineer-to-Order Industry: A Case Study. In: Umeda, S., Nakano, M., Mizuyama, H., Hibino, H., Kiritsis, D., Cieminski, G.v. (eds.) Advances in Production Management Systems: Innovative Production Management Towards Sustainable Growth. No. 460 in IFIP Advances in Information and Communication Technology, Springer International Publishing (2015)

16. Semini, M., Haartveit, D.E.G., Alfnes, E., Arica, E., Brett, P.O., Strandhagen, J.O.: Strategies for Customized Shipbuilding with Different Customer Order Decoupling Points. Proceedings of the Institution of Mechanical Engineers 228(4), 362-372 (2014)

17. Grabenstetter, D.H., Usher, J.M.: Developing Due Dates in an Engineer-to-order Engineering Environment. Int. J. of Produc. Res. 52(21), 6349-6361 (2014) 